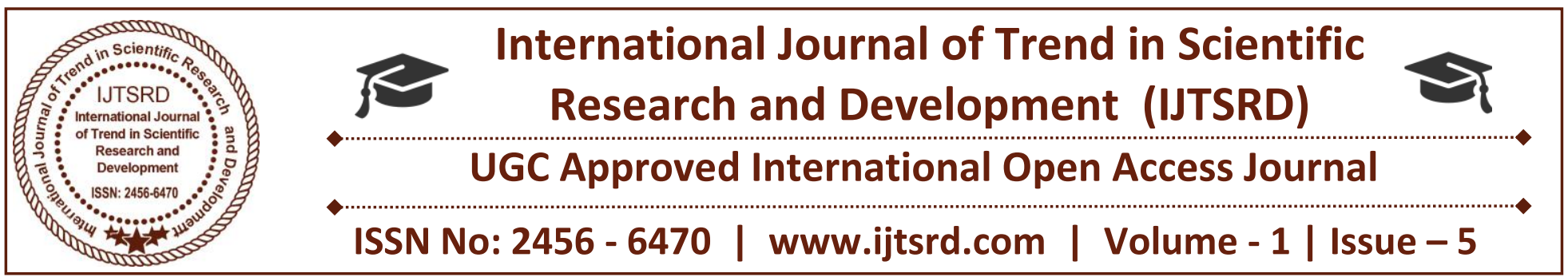

\title{
Thumb Rules for Sustainabile Learning Environment
}

\author{
Monika Shekhar Gupta \\ Associate Professor \\ Amity School of Architecture and Planning, \\ Madhya Pradesh, Gwalior
}

\begin{abstract}
The environment must be specially protected as it is one of the most basic public assets of a human system. Sustainable development approves ecological limitation under the economic activity frame and it has full comprehension for support of human needs but it is understood as a development that does not damage the ecological or social systems on which it depends.
\end{abstract}

School is the place where young minds are shaped and also have significant impact on the environment through their embodied and operational use of resources. The paper addresses the importance of significant impact on the ability of the teacher to teach and the learner to learn School design. Large investments are being made for the renewal of existing schools and for the designing of new ones along Ecological Sustainable Design (ESD) or 'green' principles. For producing greener schools, it is important that one must not forget that that these spaces need to work well pedagogically as well as ecologically. The schools must be designed in such manner that they should provide effective healthy learning spaces that use energy, water and resources efficiently.

This paper briefly introduces Green Star Education and how it is used, but its main focus is on those aspects of the rating tool that relate to the provision of effective learning environments that will lead to a suggested definition of what it might mean to create effective, 'green' learning environments.

This paper discusses Effective Learning Environments (ELEs) support teaching and learning by providing the appropriate facilities and environments to carry out learning activities.

The paper concludes with recommendations to find ways that can be used for future concepts.

Keywords: Effective learning environment, Indoor environment quality, smart techniques and materials

\section{INTRODUCTION}

A definition of an Effective Green Learning Environment is:

An environment that is adequately lit, ventilated, thermally comfortable and acoustically effective spaces that supports teaching and learning through resource efficient construction and operation. Further, EGLEs provide opportunities for tacit learning through interaction, understanding and engagement with the building, systems and space.

Current pedagogical requirement is the design of EGLEs that requires the use of established strategies for the 'green' design of schools but also the inclusion of expertise from project inception. A current Australian Research Council project called 'Smart Green Schools' has brought together a multidisciplinary team of educators, architects and ESD experts to explore these issues.

Guidelines and checklists have been developed in many countries to support the design and construction of effective 'green' learning spaces, building rating tools. They are only useful in as far as they facilitate the design of effective learning environments. 
Green Star rating system was created to:

$>$ establishing a common language and standard of measurement that

$>$ define green building

$>$ promote integrated, whole building design;

$>$ identify building life-cycle impacts;

$>$ raise awareness of green building benefits;

$>$ recognize and reward environmental leadership; and

$>$ transform the built environment to reduce the environmental impact of development. Learning effectiveness is highly effected by lighting, ventilation and water proofing by providing adequate thermal comfort and minimizing acoustic problems.

\section{LIGHTING}

The Heschong Mahone Group14 showed that the effects from the introduction of controlled natural daylight to classrooms, along with allowing views to the outdoors, resulted in an increase in student achievement of 26 per cent. In addition, Shum Miller15 showed that daylight in classrooms can have an impact on reducing illness, absenteeism and an improvement in student behavior. Most effective daylighting strategies are controlled by heat gain and the amount of light and glare.A space could be illuminated by an extra 25 per cent through proper use of indirect light either by allowing light in from the south (for the southern hemisphere, north for the northern hemisphere) or bouncing it in through light shelves.

Significant savings on operational lighting costs can be achieved through effective natural and artificial lighting. For example, it is not necessary to have uniform lighting across an entire classroom, varying the lighting allows for the

High lighting of spaces and the differentiation of activities and will lead to energy saving. Long term savings can be achieved through the future proofing of function through design for retrofitting by using different luminaries, diffusers or adaptive switching strategies.

The classroom must use $90 \%$ natural daylight which translates to an $80 \%$ saving in energy. This is achieved using tubular skylights (with adjustable light damper), large low E double glazed windows and energy efficient dimming lights that are programmed to respond to external conditions. The occupant can override the sensor and choose to activate $50 \%$ or $100 \%$ of the lighting, where $50 \%$ controls one lamp per fixture (not $50 \%$ of the whole room). The large expanses of glazing are well controlled by generous overhangs and automatically controlled blinds. The standard option has glazing to $700 \mathrm{~mm}$ above floor level, and there are options for the glazing to come down to the ground, so younger students can see out. An AV switch automatically prepares the room for use of overhead projection

\section{AIR QUALITY AND VENTILATION}

"Ongoing research and scientific analysis contributes to provide evidence that IAQ [Indoor Air Quality] in schools can cause acute health symptoms, increase absenteeism, and directly and indirectly affect student and teacher performance... experts in the field generally agree that healthy indoor school environments are a necessity if a high standard of education is to be expected." Mould, dust and pollen have an impact on indoor air quality (IAQ) and can affect children with asthma. The impact of these need to be minimized by appropriate air filtration, education of building users about when to close windows and control of moisture.

There is a direct link between poor air quality and respiratory illness such as asthma. In the US asthma is the cause of an average 4.6 missed days of school per child annually [Wakefield 2002].

The link between respiratory illnesses such as asthma and mould has been thoroughly demonstrated in medical research.17 Mould commonly occurs in poorly water proofed and ventilated buildings. Thus effective green learning spaces must be designed to ensure that areas where mould typically occurs are eliminated.

\section{INDOOR ENVIRONMENT QUALITY OR IEQ}

An integral part of the entire building performance is IEQ. IEQ relates to the combined impact of environmental parameters such as indoor air quality (IAQ), thermal comfort, light and acoustics. IAQ is an assessment of dust particle matter (PM), mould, pollen, $\mathrm{CO} 2$ and Volatile Organic Compounds (VOCs) in the air. There is a direct relationship between IEQ and the comfort and productivity of building inhabitants.IEQ is impacted on by thermal comfort which includes: air temperature, mean radiant temperature, relative humidity, air velocity and rate of air change. [1] 
According to Edwards:. it appears evident that those green schools which give priority to daylight and natural ventilation generally outperform other schools specifically through ensuring relative humidity is controlled in mechanically ventilated buildings (60 per cent relative humidity in space and 80 per cent relative humidity in ductwork) or by specifying naturally ventilated buildings (IEQ-10Mould Prevention). Limiting the ability for moisture to build up has the added benefit limiting that aspect in the degradation of buildings, leading to longer lasting facilities and therefore a better return on financial and environmental investments.[3]

\section{Green Star: IAQ}

$>$ Dry bulb temperature of $20-24^{\circ} \mathrm{C}$ and a mean radiant temp of $20-27^{\circ} \mathrm{C}$ or shading so that there is no radiant load on the glass

$>$ Relative Humidity 40-60\%

$>$ Air velocity $<0.2 \mathrm{~m} / \mathrm{s}$ unless occupants have control of air direction

> Double glazing to $90 \%$ of glass $100 \%$ of N W E and $15 \%$ improvement on BCA glazing compliance.

\section{THERMAL COMFORT}

Research into thermal comfort showed that being comfortable positively impacted on students' performance in terms of attention, comprehension and learning levels. This finding is supported by other international research [Seppänen et al 2004; Pepler \& Warner 1968; Wyon 1970; Wargocki \& Wyon 2006 and 2007] which concluded that students were less distracted and less likely to become ill if the classroom environment stayed between the comfort band of $20-27^{\circ} \mathrm{C}$.

Richard de Dear concluded that there are productivity benefits (through the perception of comfort by building users) if the indoor temperature reflects the outdoor temperature more closely, particularly if they have control over their environment. From an operational energy perspective this means that the temperature bands do not need to be as narrow.

\section{ACOUSTICS}

Many schools aiming to integrate ESD and a more flexible approach to the use of space have large open areas to allow multiple activities and though this offers good opportunities for daylighting and cross ventilation it often results in poor acoustic performance. Careful analysis of the potential internal and external noise levels when considering space design is crucial. Often, within the design process, the acoustic analysis is carried out too late requiring either a change in the design or expensive retrofitting. Bringing in the acoustic engineers earlier will help minimize this extra effort ensuring an integrated design minimizing the chance that acoustic treatments are removed as a cost cutting exercise.

A holistic approach must be taken to address acoustics. A wide range of internal and external factors such as traffic, plant, lighting, finishes, ventilation system and adjoining rooms impact on background noise and reverberation times [Ecophon 2002]. There is a direct relationship between good acoustics and effective learning [Evans \& Maxwell 1997]. Consideration of classroom acoustics is particularly important with changing pedagogical models as they involve more group and project work [Ecophon 2002]. Poor classroom acoustics is also attributed to voice disorders and stress amongst teachers [Wakefield 2002, Ecophon 2002].

A reduction in the total area of hard surfaces in a space is key for embedding good acoustics. Careful consideration should also be given to selection of Heating Ventilation and Air Conditioning (HVAC) systems. Sound absorbing ceilings and acoustic wall panels also effectively reduce the noise levels experienced in a classroom.

\section{MATERIALS}

The material used is a key consideration for the design and development of re-locatable classrooms. There are inherent waste and efficiency opportunities that off-site manufacture presents. It is important to consider the choice of materials, optimizing re-use and recycling where possible and minimizing embodied energy - but not at the cost of maintainability, strength and longevity. The materials chosen must have low maintenance, either contained recycled material or recyclable and have no or low VOCs. The project can achieve $100 \%$ recycled mineral-board sheeting for roof and wall backing, $80 \%$ recycled content in the steel and $100 \%$ recycled denim for insulation.

Use of post-consumer recycled to be $20 \%$ or greater;

Reuse of materials - $2 \%$ or greater; 
Minimize Portland cement use; substitute with industrial waste such as flyash; use recycled aggregate;

$>$ Steel should be $50 \%$ post consumer recycled steel or be reused;

$>$ Minimize PVC usage;

$>$ Timber should be FSC certified, post consumer recycled or reused.

$>$ Design for ease of disassembly;

$>$ Plan dematerialization, for example minimize need for painting, ductwork, piping;

$>$ Use durable flooring that is low maintenance, modular, low emission and low impact;

$>$ Joinery and furniture to be low emission, durable, low maintenance, modular and low impact;

$>$ Integrate space for recycled materials and waste materials for recycling.[1]

\section{PRODUCTS THAT CAN BE USED FOR FUTURE CONCEPT}

\subsection{Solar Air Heaters}

Solar air heaters are used for providing heating in winter passively. For specifying solar air heaters and for proper functioning they need the sun to shine, so consideration of solar hours is very important and must be taken into account. A conventional solar air heater is essentially a flat plate collector with absorber plate, a transparent cover system at the top and insulation at the bottom and on the sides assembled and encased in a sheet metal container. The working fluid is air, though the passage for its flow varies according to the type of air heater. Materials for construction of air heaters are similar to those of liquid flat plate collectors. The transmission of solar radiation through the cover system and its subsequent absorption in the absorber plate can be given by expressions identical to that of liquid flat plate collectors. Selective coating on the absorber plate can be used to improve the collection efficiency but cost effectiveness criterion should be kept in mind.

$>$ The need to transfer heat from working fluids to another fluid is eliminated as air is being used directly as the working substance. The system is compact and less complicated.

$>$ Corrosion is a great problem in solar water heater. And this problem is not experienced in solar air heaters.

$>$ Leakage of air from the duct does not create any problem.
$>$ Freezing of working fluid virtually does not exist.

$>$ The pressure inside the collector does not become very high.

Thus air heater can be designed using cheaper as well as lesser amount of material and it is simpler to use than the solar water heaters.[5]

\subsection{SMART BREEZE}

This is a solar powered ventilation system that can help with passive heating or cooling. These systems have been introduced into the Department of Education and Early Childhood Development's most recent relocatable classrooms 2 .

$>$ Designed and made in Australia

$>$ Roof mounted box

$>$ Uses filtered hot air from the roof cavity for heating

Can also purge hot air from the roof cavity or suck in cool air from outside for cooling.[14]

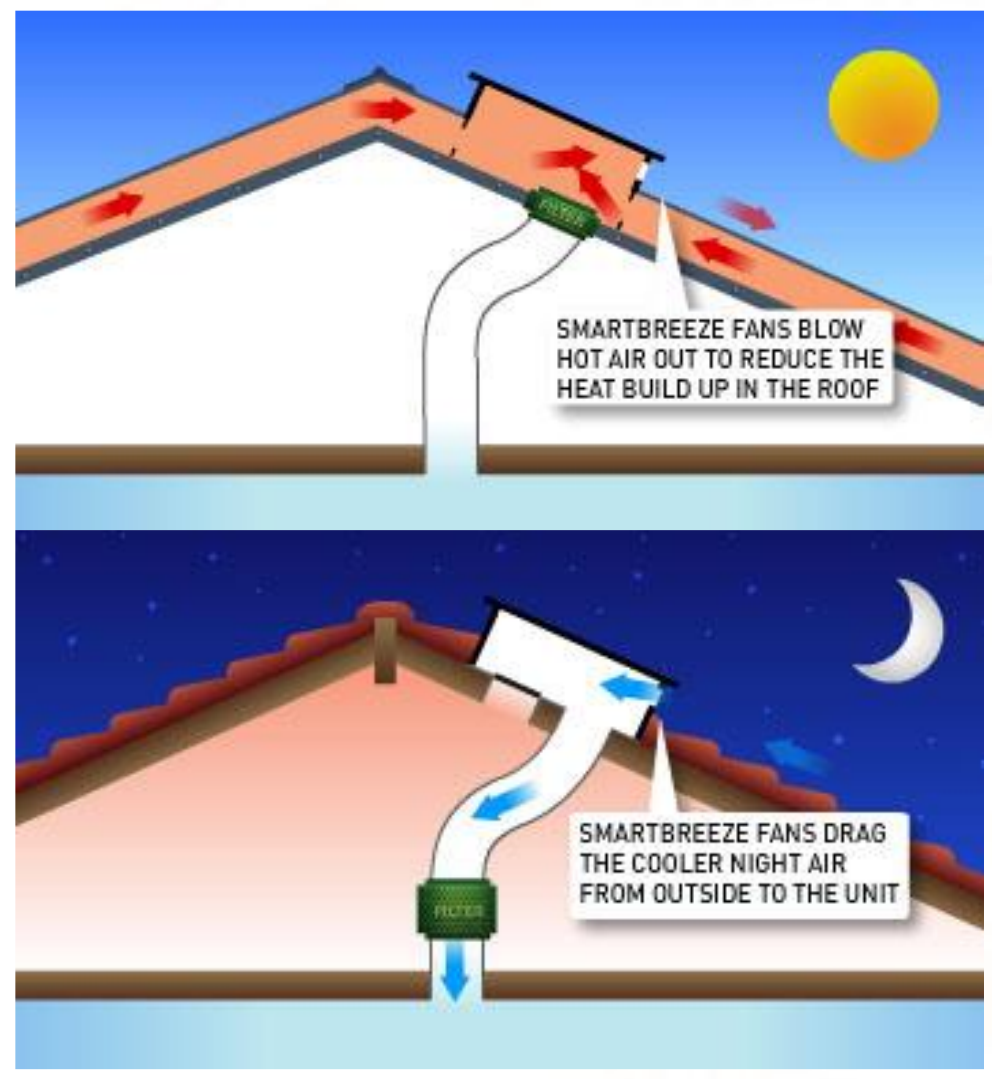

\subsection{SOLATUBE LIGHTS}

High-performance daylighting systems that use advanced optics to significantly improve the way daylight is harnessed. The Smart LED System was designed to operate individually to illuminate small areas or in dual configurations to attain predictable 
lighting results for medium-sized spaces. It also can be used to create specific architectural effects using wall washes and soffit lighting, making the Smart LED System an intelligent solution for achieving ambient light levels in spaces with ceiling heights up to $10 \mathrm{ft}$.

\section{Reduces energy costs}

During the day, the Smart LED System lights interiors using no-cost, natural light. As the sun starts to set and light levels fall, energy-efficient LEDs activate automatically to provide illumination for early morning and evening use. The result is a commercial daylighting solution that significantly cuts electricity use and delivers up to $94 \%$ in light energy savings. Unlike traditional light sources, LEDs expend significantly less energy to produce light. For this reason, they can last up to three times longer than compact fluorescent lamps, eight times longer than halogen lamps, and a whopping 25 times longer than incandescent lamps. The LED bulbs in the Smart LED System are designed to last up to 20 years, making maintenance easier since re-lamping will be unnecessary for decades.

\section{Seasonal adaptability}

Adequate light output is important for occupant satisfaction and productivity. The Smart LED System's unique dual lighting design makes it extremely effective at delivering consistent lighting, regardless of hour or season. In winter, when days are shorter, daylight is supplemented by the system's
LEDs to ensure minimum lighting requirements are met throughout the day. In the spring and summer, when days are longer and more daylight is available, the LEDs are triggered only in the early morning and evening when they're needed. [11]

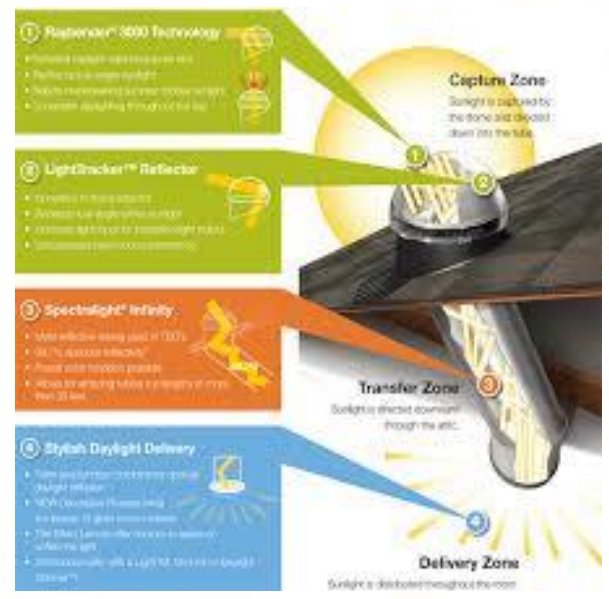

\subsection{CO2 Living Glass}

This is a prototype of a glass that senses when there is too much $\mathrm{CO} 2$ and expels it so that you do not need to mechanically ventilate4.Soo-in Yang and David Benjamin, architects at. The Living have come up with a new material called "Living Glass" that will look out for your health by monitoring $\mathrm{CO} 2$ levels in the air. The new smart material is a thin, transparent, non-mechanical surface which automatically opens and closes "gills" in response to human presence to control the air quality in the room. The silicone surface embedded with Dynalloy Flexinol wires contracts due to the electrical stimulus, allowing the "gills" to breathe and regulate air quality when carbon dioxide levels are high. [12] 

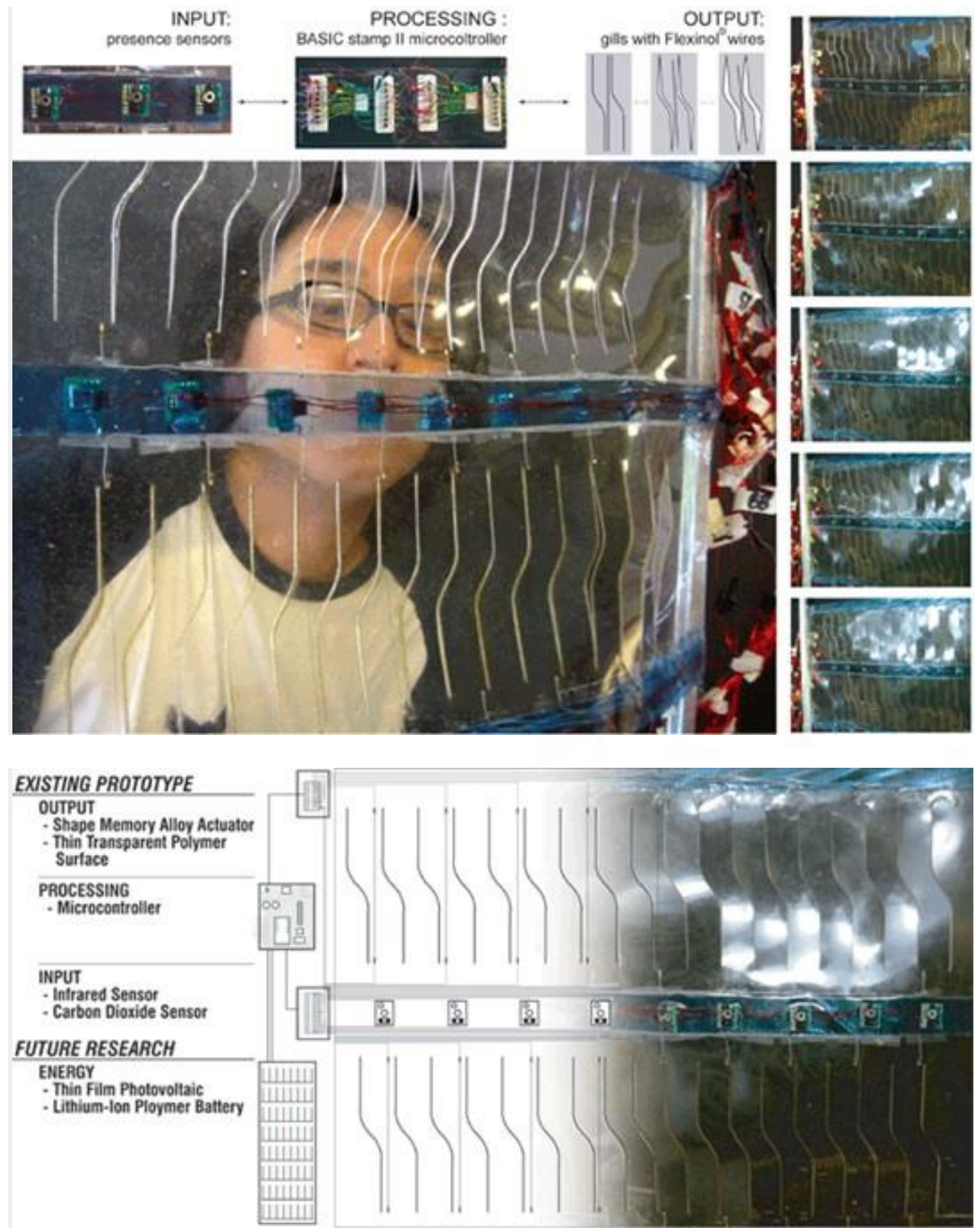

\subsection{Cross Laminated Timber}

This timber structural panel product6 - also known as CLT - has been used in Europe for the past 20 years. More recently it has been used on prefabricated building projects in London such as the 9 storey high Stadthaus Tower Murray Grove by Waugh Thistleton and the Kingsdale School Sports and Music Hall. It is used mainly for wall, ceiling and roof construction. Cross-laminated Timber (CLT) being a new generation of engineered wood product, provides a

great potential for use in Canada and the US in both residential and non-residential construction applications. The superior attributes of the CLT panels and assemblies such as good fire and seismic resistance, excellent sound and thermal insulation properties combined with ease of fabrication, quick assembly, and many environmental advantages makes CLT a preferred choice by designers and clients in some types of construction. CLT panels consist of several layers of structural lumber boards stacked crosswise (typically at 90 degrees) and glued together on their wide faces and, sometimes, on the narrow faces as well. A cross-section of a CLT element has at least three glued layers of boards placed in orthogonally alternating orientation to the neighboring 
layers. In special configurations, consecutive layers may be placed in the same direction, giving a double layer (e.g. double longitudinal layers at the outer faces and additional double layers at the core of the panel) to obtain specific structural capacities. CLT products are usually fabricated with three to seven layers and even more in some cases. Figure 1 includes a diagram and photograph of a CLT panel configuration while Figure 2 is a diagram of possible CLT panel crosssections. Figure 3 is a diagram of a 5-layer CLT panel including both cross-sectional views.

Cross-laminated timber used for prefabricated wall and floor panels offers many advantages. The cross laminating process provides improved dimensional stability to the product which allows for prefabrication of wide and long floor slabs and single story long walls. Additionally, cross-laminating provides relatively high in-plane and out-of-plane strength and stiffness properties in both directions, giving these panels a two-way action capability similar to a reinforced concrete slab. The 'reinforcement' effect provided by the cross lamination in CLT also considerably increases the splitting resistance of CLT for certain types of connection systems. [4]

\subsection{PCM Plasterboard}

Phase change materials (PCMs) can store much larger amounts of thermal energy per unit mass than conventional building materials. PCM Plasterboard is an exciting example.7 this allows designers to think about the use of thermal mass (PCM acts like it) and night purge in light weight buildings. An effective way to maintain a pleasant temperature in summer is to increase the thermal capacity of a structure. By absorbing heat in walls or ceilings and releasing it at the right moment, thermal mass acts as a buffer against temperature fluctuations. This is especially true for lightweight structures, which are more prone to overheating in the summer.

Knauf Comfortboard achieves thermal mass, but at a fraction of the weight, giving savings across the build programme. And because it's so simple to install, Knauf Comfortboard is also ideal for upgrading thermal performance in existing buildings as the room temperature rises the heat energy transfers to the board and heats the wax changing it from a solid to a liquid within the glass beads. This means that the board is essentially taking the heat out of the room allowing it to remain at a constant comfortable temperature. At night the board will cool back down, especially if the windows are open for ventilation, and the wax will return to a solid, meaning that the next day it will be ready to absorb the heat energy once more.

Knauf Comfortboard will continue to work in this cycle, maintenance free, for the lifetime of the building. Knauf Comfortboard is a quick and simple way to add thermal mass to any building. It can be scored and snapped, just like any other plasterboard, and is fixed in the same way to timber and metal substructures in walls and ceilings. Once fitted, Knauf Comfortboard can be taped and jointed or skim plastered to achieve a high-quality finish.[10]

\subsection{Transparent Concrete}

Provides thermal mass while allowing light and connection to external conditions. The main advantage of transparent concrete is that it can transmit light. There, it can be used to make green buildings. Since it can transmit light from natural as well as artificial sources, the building can have fewer lights to meet its demand for lighting. Thus saving huge energy cost. Transparent concrete uses sunlight as source of light instead of electrical energy and reduces power consumption. This concrete can also be used cold countries to transmit heat with sunlight. Transparent concrete is manufactured by using combination of fiber optics and fine concrete. These fibers blend into the concrete like any other aggregates. These optical fibers can transmit light from natural and artificial sources into spaces enclosed by the translucent concrete panels. The main reason for using optical fiber in concrete is that it can transmit light even an incident angle greater than $60^{\circ}$.Optical fiber consists of three layers called as core, cladding and buffer coating or jacket. The light is transmitted through the core of the optical fiber. Transparent concrete is manufactured using fine materials only. It does not contain coarse aggregates. This concrete can have the compressive strength of that of high strength concrete around $70 \mathrm{MPa}$.[6]

\subsection{Bio Walls}

BioWall is a thin profile, closed-loop interior ecosystem. It's comprised of tropical plants, soilless media, and a waterproof backing. BioWall thrives in a bright indoor location; energy efficient lighting can be supplemented in locations that do not have adequate natural light. BioWall reduces the demand for energy 
consumptive mechanical air filtration systems by harnessing the natural phytoremediation capabilities of tropical plants. This process effectively removes common airborne pollutants. Indoor air quality is one of the least discussed environmental dangers, yet one of the most serious threats affecting our health. Most of us spend the majority of our time indoors, and poor indoor air quality leaves us susceptible to serious long- and short-term health problems. BioWall is a vegetated wall that naturally filters air and removes several harmful pollutants. On top of that, BioWall offers a dramatic aesthetic $-a$ wow factor. Bio Wall's cost is comparable to several other high-end interior finishes. Research indicates that interior plants can dramatically increase our happiness and productivity through biophilia. Biowalls (living walls, vertical gardens, green facades and green walls) are exterior walls that are covered with living vegetation and used to insulate the building and improve air quality.

The Thermal Displacement Ventilation (TDV) system provides $100 \%$ fresh filtered air to the students at a low velocity. A $\mathrm{CO} 2$ sensor communicates when oxygen levels are low. Sensors on the doors and windows switch the TDV from mechanical to natural ventilation mode when doors and/or windows have been open for 15 minutes. The system saves $35 \%$ in energy and is extremely quiet, having no detectable impact on acoustics.

\section{CONCLUSION}

There have been several studies undertaken on school effectiveness and the influence of the learning environment on education [Fraser 1986; Sammons et al 1996; Walberg 1981]. The research underlines the complexity of effective school environments, emphasizing that success is not dependent on one solution or single characteristic.

Studies into Indoor Environment Quality (IEQ) and occupant productivity show that the quality of the indoor environment can impact both positively and negatively on effective learning. All the design strategies outlined above require not only appropriate design consideration but also an understanding by the building occupants of when to open windows, close blinds and turn off lights, in order to maximize its ESD performance green building perform best if they have green occupants.

The aim of this paper was to reflect on those credits that support both more environmentally friendly building and effective learning outcomes. It is interesting to note that those credits related to more effective learning outcomes, as discussed here, only make up a small percentage of the total credits available25. This raises the question: should a tool such as Green Star just focus on environmental performance and ignore the less quantitative issues of comfort and student performance, or is a more complex tool that includes learning effectiveness, pedagogical and curriculum aspects required? For now, ensuring the educators and students have a voice in the design alongside the use of Green Star seems to be the best way forward.

Creating and maintaining stimulating learning environments can be achieved through interactive and whole school displays and a climate of innovation. The future holds many challenges for young people, such as climate change and global poverty.

It is clear that our current model of development and use of resources is placing an increasing burden on the environment, but $21^{\text {st }}$ Century schools should be designed to sustain learning and learners minimizing the destruction of limited environmental resources. Schools have a special role to play in rebuilding and protecting the environment. As places of learning, they can help pupils understand our impact on the environment; and become places where sustainable living and working is demonstrated to young people and the community. This study seeks to influence school designers, administrators, teachers and investors to develop schools that favor natural or outdoor learning environments, as the traditional classroom is not sustainable enough.

\section{REFERENCES}

1) futureproofingschools.com

2) emedesign.com.au

3) webcache.googleusercontent.com

4) www.forestprod.org

5) mechanicalinventions.blogspot.com

6) theconstructor.org

7) furbishco.com

8) www.seameo.org

9) www.solatube.com

10) www.knauf.co.uk

11) commercial.solatube.com.au

12) www.inhabitat.com

13) www.science.gov

14) www.greenrenovation.com.au 